\title{
Continuous Stirred Tank Reactor: A Process Design for Interesterification of Macauba (Acrocomia aculeata) palm oil
}

\author{
Pedro Prates Valério ${ }^{a^{*}}$, Isabella Fonseca Araujo ${ }^{\mathrm{b}}$, Juan Canellas Bosch \\ Neto $^{\mathrm{b}}$, Jesus Maria Frias Celayeta ${ }^{\mathrm{c}}$, and Erika Cristina Cren $^{\mathrm{a}}$ \\ ${ }^{a}$ Chemical Engineering Department, Federal University of Minas Gerais - UFMG. Brazil \\ b Chemical Engineering Department, Federal University of São João del-Rei - UFSJ. Brazil \\ ${ }^{\mathrm{c}}$ Environmental Sustainability and Health Institute - Dublin Institute of Technology - DIT. Ireland \\ ${ }^{*}$ Corresponding author \\ pedroprates@ufmg.br \\ TEL.: +55-31-99345-1535
}

Received: 31 October 2018; Published online: 18 April 2021

Invited paper from the $5^{\text {th }}$ International ISEKI Food Conference - ISEKI Food 2018 - The Food System Approach - New challenges for Education, Research and Industry

\begin{abstract}
Other than the edible oils extracted from the Acrocomia aculeata fruit, there is a growing interest in the palm to generate other high value-added products. Relatively high amounts of carotenoids (up to $378 \mathrm{mg} \mathrm{kg}^{-1}$ ) have been found in the esculent oils mechanically obtained from the fruit mesocarp. From industrial application perspectives, several processes have been proposed to modify native vegetable oils to yield high functional properties of structured lipids. For interesterified products, the thermal effects of industrial reactors are crucial in reaction mechanisms. The present study has taken into account previously estimated kinetic parameters for the overall disappearances of all-trans $\beta$-carotene in the Acrocomia aculeata oil $\left(k_{o}=2.6 \times 10^{-4} \mathrm{~min}^{-1} ; \mathrm{Ea}=105.0003 \mathrm{~kJ} \mathrm{~mol}^{-1} ; \Delta \mathrm{H}=9.8 \times 104 \mathrm{~J} \mathrm{~kg}^{-1}\right)$ to develop a continuous stirred tank reactor (CSTR) kinetic treatment that obeys first-order kinetics. A system of ordinary differential equations - mass and energy balances - was solved by the $4^{\text {th }}$ order Runge-Kutta method (GNU Octave software). Under research conditions related to interesterification processing $(2 \mathrm{~h} ; 393.15 \mathrm{~K})$, the initial concentration of carotenoids (around $11 \%$ ) showed no significant decrease. Overall, realistic processing effects and conditions have been assessed, integrating results and knowledge, improving prospects of Acrocomia aculeata as a promising source of high-quality raw material, for producing functional ingredients and food with nutraceutical properties.
\end{abstract}

Keywords: Mathematical Modelling; CSTR; Runge-Kutta; Kinetics; Carotenoids; Interesterification

\section{Introduction}

Several industrial processes have been proposed to modify crude vegetable oils to meet the demands of contemporary consumers. These modifications are usually carried out to address functional characteristics of structured lipids (Xie \& Chen, 2014; Xie, Yang \& Zang, 2015; Xu, 2000). Among the most commonly applied methods to tailor physicochemical properties of edible oils, interesterification has received considerable attention. Unlike hydrogenation, interesterification processes are not related to the formation of trans fatty acids, therefore, extending the commercial application of modified lipids, including those with functional properties (Zhang, Lee, Zhou \& Wang, 2019).

Interesterification processes can be carried out 
chemically or enzymatically, to reposition fatty acids on triacylglycerol structures. The process consists of ester breakages to form new aleatory bonds. Chemical interesterification is a process in which low-acid vegetable oils are not necessarily required to be previously bleached. Being relatively inexpensive when compared to enzymatic interesterification, the method is amenable to be scaled up being both efficient and feasible (Dijkstra, 2015; Tourchi Rudsari, Najafian \& Shahidi, 2019).

Increasing demand by consumers and industries for new sources of natural food and products has been shown. The consumption of these products tends to be associated with health-related benefits obtained from bioactive compounds, among which fatty acids, carotenoids, and micronutrients constitute essential classes (Babbar, Oberoi \& Sandhu, 2015; Cataldo, López, Cárcamo \& Agosin, 2016; Oloo, Shitandi, Mahungu, Malinga \& Ogata, 2014).

With a similar productive potential to Elaeis guineensis, Macauba (Acrocomia aculeata) is a high oil-yielding plant suited to edaphoclimatic zones, conditions adverse to African palms. An adult palm fructifies continuously with productivity from 4 to 6 tonnes of esculent oil per hectare. The oil extracted from the mesocarp is edible, containing up to $378 \mathrm{mg} \mathrm{kg}^{-1}$ of total carotenoids, with no antinutritional factors. It has a predominance of unsaturated fatty acids $(77 \%)$, of which $53 \%$ and $18 \%$ are oleic $(\omega-9)$ and linoleic $(\omega-6)$, respectively. Contrarily, the oil extracted from the kernel has a predominance of saturated fatty acids (74\%), of which $44 \%$ and $9 \%$ are lauric and palmitic, respectively (Evaristo et al., 2016; Nunes, Favaro, Galvani \& Miranda, 2015).

From the perspective of lipid processing and structuring lipids, Macauba oils can be used as raw materials for producing different blends of vegetable oils to enhance the nutritional characteristics of structured lipids with specific functional properties. In this respect, thermal treatment control is essential for the retention of several bioactive compounds in vegetable oils (Pardauil et al., 2017; Tourchi Rudsari et al., 2019; Zhang et al., 2019).

The rate of degradation reactions tends to increase dramatically during thermal treatment mainly due to heating time and variations in temperature upsurges, particularly for carotenoids. Oxidation and cleavage products, in addition to 9 -cis- $\beta$-carotene and 13 -cis- $\beta$-carotene isomers, are major compound alterations that occur during thermal processing (Achir, Randrianatoandro, Bohuon, Laffargue \& Avallone, 2010; Knockaert et al., 2012; Sampaio et al., 2013).

Previous kinetic evaluation of carotenoids degradation in vegetable oil importantly indicates a first-order reaction kinetic mechanism (AparicioRuiz, Isabel Minguez-Mosquera \& GandulRojas, 2011; Knockaert et al., 2012). Through mathematical and predictive modelling and simulation, industries can benefit from the use of kinetic data and procedures to enhance knowledge and understanding of thermal food processing (Dinh, Sun \& McLean, 2016; Singh, Singh \& Ramaswamy, 2015).

The present study was undertaken primarily to develop a continuous version of the kinetic treatment of total carotenoids degradation reactions, through mathematical and predictive modelling, considering the thermal effects of conventional processes conditions usually applied for the interesterification of vegetable oils.

\section{Materials and Methods}

\subsection{Crude Oil: Acrocomia aculeata}

Acrocomia aculeata fruit was collected from native palms within a maximum of five days after the fall in the area of the Federal University of Minas Gerais - UFMG, in the metropolitan region of Belo Horizonte, Minas Gerais, Brazil. The mesocarp and kernel portions were promptly separated from the fruit, immediately frozen to a temperature of $-18{ }^{\circ} \mathrm{C}$ and stored for up to 40 days. The mesocarp and kernel portions were thawed at room temperature, air-dried at $60{ }^{\circ} \mathrm{C}$ for 48 hours, and comminuted in a stainless-steel industrial blender (Omcan 31502, Mississauga, Canada) (Goula, 2013; Valério, 2017). The mesocarp and kernel pressings were performed on different days, to avoid cross-contamination. Crude edible oils were then mechanically ob- 
tained from the mesocarp and kernel of Acrocomia aculeata fruit by continuously operated Expeller ${ }^{\circledR}$ press coupled to an electric motor (Sew-Eurodrive AAF67 DZ100LS4, Mealhada, Portugal). Amber glass vials $(15 \mathrm{~mL})$ were filled to the brim with the samples, minimizing the impact of light and oxygen intrusion by reducing the volume of headspace. Samples were stored at freezing temperature $\left(-18{ }^{\circ} \mathrm{C}\right)$ until the analysis, to minimize possible rates and extents of enzymatic lipolysis, also concerning potential losses of antioxidants (Koidis \& Boskou, 2015; Parducci \& Fennema, 1978). For setup purposes, the content of total carotenoids in the crude $A c$ rocomia aculeata mesocarp oil was defined as 378 $\mathrm{mg} \mathrm{kg}^{-1}$. The oil specific heat and density were stated as $107400\left(\mathrm{~J} \mathrm{~kg}^{-1} \mathrm{~min}^{-1}\right)$ and $900 \mathrm{~kg}$ $\mathrm{m}^{-3}$, respectively (CETEC, 1983; Fasina \& Colley, 2008; Nunes et al., 2015).

\section{$2.2 \quad$ Fatty acid compositions}

Fatty acid compositions were determined based on the methods previously optimized by Christie (1989) and Guo, Hu, Qian and Wu (2012). The analysis was carried out on a GC 2010 System (Shimadzu, Japan) fitted with a Flame Ionisation Detector. Quantification of individual fatty acids methyl esters - FAME was conducted with a standard mixture of 37 esters of fatty acids ( $\mathrm{Su}-$ pelco, Bellefonte, Pa., USA). The analysis was performed in triplicate. Samples were compared by Tukey multi comparison test $(\mathrm{p}<0.05)$. Results were expressed considering the mean and sample standard deviation for the fatty acid composition, being expressed as a percentage of total fatty acids. The positive square root of variance formula is given according to the following Equation 1.

$$
S=\sqrt{\frac{\sum\left(X_{i}-\tilde{X}\right)^{2}}{n-1}}
$$

In the above equation, $S$ is the sample standard deviation, $X_{i}$ is the sample measurement, $\tilde{X}$ is the sample arithmetic mean and $n$ is the number of replicates.

\subsection{Acid value}

The Acid Value (AV) for the Acrocomia aculeata mesocarp oil was determined according to the AOCS Official Method 3d Cd-63 (AOCS, 2009). Determinations were performed by diluting $1 \mathrm{~g}$ of oil in $50 \mathrm{~mL}$ solution of isopropanol:toluene (1:1) followed by titration with potassium hydroxide $\left(0.1 \mathrm{~mol} \mathrm{~L}^{-1}\right)$ standardized with potassium biphthalate. Values were calculated by the Equations (2) and (3) and presented; considering the mean and standard deviation, for the analysis performed in triplicate.

$$
\begin{aligned}
& A V\left(m g \text { KOH. } g^{-1}\right)=\frac{(A-B) \times M \times 56.1}{W} \\
& A V(\% \text { oleic acid })=\frac{(A-B) \times M \times 28.2}{W}
\end{aligned}
$$

In the above equations, $A$ and $B$ are the volume $(\mathrm{mL})$ of potassium hydroxide $(\mathrm{KOH})$ used for the sample and blank titration, respectively. $M$ is the molarity of the applied basic solution, after standardization, and $W$ is the sample weight $(\mathrm{g})$.

\subsection{Apparent kinetic and thermodynamic parameters}

Apparent kinetic and thermodynamic parameters were previously estimated in a batch system (Valério, 2017), regarding the overall disappearances of total carotenoids naturally present in the mesocarp oil. The activation energy $\left(E_{a}\right)$ of $105000.3 \mathrm{~J} \mathrm{~mol}^{-1}$ and the rate constant $(k)$ of $2.6 \times 10^{-4} \mathrm{~min}^{-1}$ were estimated by nonlinear regression, also considering the Arrhenius law. The enthalpy of activation $(\Delta \mathrm{H})$ of $9.81 \times 104 \mathrm{~J}$ $\mathrm{kg}^{-1}$ was obtained by linear regression, according to the activation complex theory (Uzun \& Ibanoglu, 2018). The parameters were then applied to the continuous version of the kinetic treatment, as seen in Table 1 of the following item 2.5.

\subsection{Mathematical and predictive modelling: mass and energy balances}

The mathematical and predictive modelling applied to the continuous version of the kinetic 
Table 1: Process parameters: simulation data for CSTR

\begin{tabular}{lcc}
\hline Parameter & Parameter Identification & Unit \\
\hline $\mathrm{F}$ & Mass Flow & $0.001 \mathrm{~kg} \mathrm{~min}^{-1}$ \\
$\mathrm{C}_{a o}$ & Carotenoids concentration (inlet) & $378 \mathrm{mg} \mathrm{kg}^{-1}$ \\
$\mathrm{R}$ & Universal Molar Gas Constant & $10.06 \mathrm{~J} \mathrm{~kg}^{-1} \mathrm{~K}^{-1}$ \\
$\mathrm{To}$ & Temperature of the Feed & 393.15 \\
$\mathrm{~V}^{a}$ & Reactor Volume & $100 \mathrm{dm}^{3}$ \\
$\rho$ & Oil Density & $900 \mathrm{~kg} \mathrm{~m}^{-3}$ \\
$\mathrm{cp}$ & specific heat & $107400 \mathrm{~J} \mathrm{~kg}^{-1} \mathrm{~min}^{-1}$ \\
$\mathrm{q}^{\prime}=\mathrm{dq} / \mathrm{dt}$ & Flux Heat & $1 \times 10^{3} \mathrm{~kJ} \mathrm{~min}^{-1}$ \\
$\mathrm{E}_{a}$ & Activation Energy & $105000.3 \mathrm{~J} \mathrm{~mol}$ \\
$\mathrm{k}_{o}$ & Rate constant & $2.6 \times 10^{-4} \mathrm{~min}^{-1}$ \\
$\Delta \mathrm{H}$ & Enthalpy of Reaction & $9.81 \times 104 \mathrm{~J} \mathrm{~kg}^{-1}$ \\
\hline
\end{tabular}

${ }^{a}$ Volume was arbitrarily defined as $100 \mathrm{dm}^{3}$ for design purpose

modelling was performed through experimental and computer simulation techniques, using a numerical solution for a system of differential equations. The overall disappearance of all carotenoids forms in the mesocarp oil was studied to determine the intensity of the tetraterpenoids oxidative reactions in a Continuous Stirred Tank Reactor - CSTR (Achir et al., 2010; Sampaio et al., 2013). Mass and energy balances were conducted according to the following Equations 4 and 5, respectively, obeying the first-order formalism (Aparicio-Ruiz et al., 2011; Knockaert et al., 2012).

$$
\begin{gathered}
F C a_{o}-F C a-k_{0} e^{\frac{-E a}{R(T a-T 0)}} C a V=V \frac{d C a}{d t} \\
\rho F C p T o-\rho F C p T a-\Delta H k_{0} e^{\frac{-E a}{R(T a-T 0)}} V+q^{\prime}=\rho V C p \frac{d T a}{d t}
\end{gathered}
$$

In the above equation, $F$ is the mass flow rate, $C_{a o}$ and $C_{a}$ are the total carotenoids concentration at the reactor inlet and outlet. $k_{o}$ is the rate constant at the reference temperature, $E_{a}$ is the activation energy, $R$ is the universal molar gas constant. $T_{o}$ is the temperature of the feed to the CSTR, $T_{a}$ is the temperature of the underflow of the CSTR, $V$ is the reactor volume, $\rho$ is the oil density, $C p$ is the specific heat, $\Delta \mathrm{H}$ is the enthalpy of reaction, and $q$ ' is the flux heat.

The equations presented were solved by a $4^{\text {th }}$ order Runge-Kutta method (GNU Octave Software, version 4.2.2 2018), from the perspective of developing and sharing both a free lan- guage program and a simple and effective solution algorithm. Thermal processing parameters were defined based on Grimaldi, Gonçalves and Ando (2005), Norizzah, Chong, Cheow and Zaliha (2004), Rodríguez, Castro, Salinas, López and Miranda (2001) and Petrauskaite, De Greyt, Kellens and Huyghebaert (1998). The isothermal temperature of $393.15 \mathrm{~K}$ was considered for the proposed time-dependent profile Dinh et al. (2016). The parameters for the CSTR simulation are presented in the following Table 1.

\section{Results and Discussion}

\subsection{Fatty acid composition}

Table 2 shows the mean and the standard deviation for the fatty acid composition (expressed as a percentage of total fatty acids) for the oils extracted from the Acrocomia aculeata mesocarp and kernel.

As it can be observed, oleic acid is predominant in the mesocarp oil. The level is similar to those (48-74\%) of palm stearin (CAC, 2015), which is widely used for interesterification purposes. The palmitic acid was the second most abundant fatty acid in the oil extracted from the fruit mesocarp, which is in agreement with previous reports (Hiane, Ramos Filho, Ramos \& Macedo, 2005; Nunes et al., 2015). Lauric acid was the predominant fatty acid in the Macauba kernel, as in 
CSTR Design for interesterification of palm oil $\mid 177$

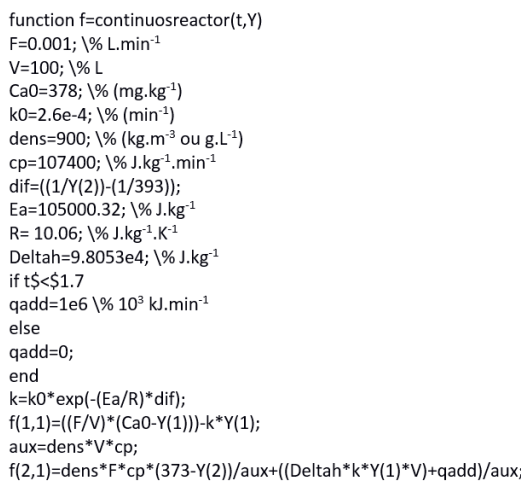

Figure 1: Algorithm: insertion of simulation data and equations

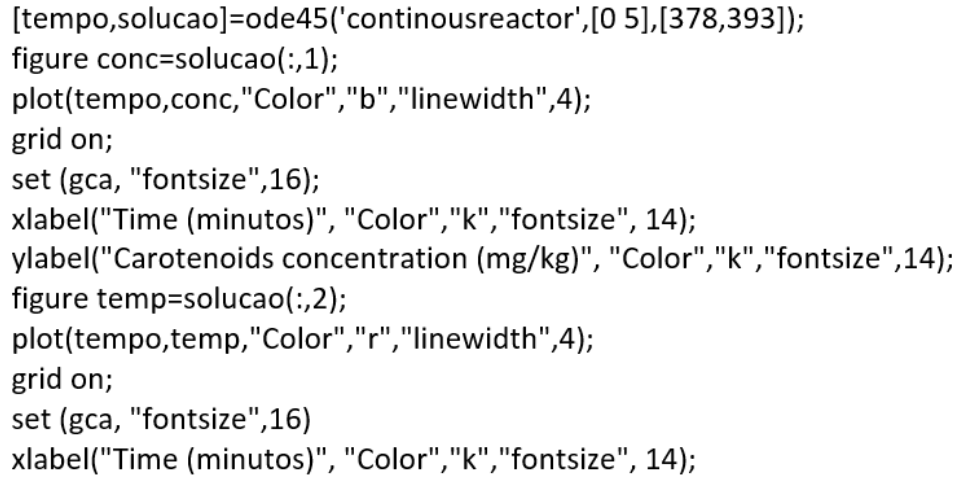

Figure 2: Computational program: Runge-Kutta solution.

other palm crops such as Attalea speciosa and in the kernel oil, kernel olein and kernel stearin of Elaeis guineensis (CAC, 2015).

The predominance of unsaturated fatty acids (MUFA: $62.11 \pm 0.84 \%$; PUFA: $11.37 \pm 1.23 \%$ ) was observed in the mesocarp oil. On the other hand, the predominance of saturated fatty acids (SFA) became apparent in the kernel oil (63.75 $\pm 0.84 \%$ ). Importantly, the levels of SFA, MUFA and PUFA were significantly different, according to Tukey's test $(\mathrm{p}<0.05)$, when comparing the mesocarp and kernel oils. Regarding the $\omega-6$ family of fatty acids, the linoleic acid in the Macauba mesocarp $(8.81 \%)$ and kernel $(3.94 \%)$ were similar to those reported (CAC, 2015) for palm oil (9.0-10.0\%), palm stearin (3.0-10.0\%), sunflower oil (2.1-17.0\%) and virgin and refined olive oils (3.5-21.0\%). The contents of linoleic acid in the Acrocomia aculeata oils were higher than those registered for palm kernel oil (1.0-3.5\%), palm kernel olein (2.4-4.3\%) and palm kernel stearin (0.5-1.5\%).

The clear distinction between the fatty acid profiles of Acrocomia aculeata mesocarp and kernel oils, especially regarding the contents of saturated and unsaturated fatty acid, already renders it an essential role as a potential alternative oil crop for interesterification purposes. The fatty acid compositions of these two types of oils are similar to other raw materials commonly blended to meet and improve functional performances of structured lipids (Xie \& Chen, 2014; Xie et al., 
$178 \mid$ Valério et al.

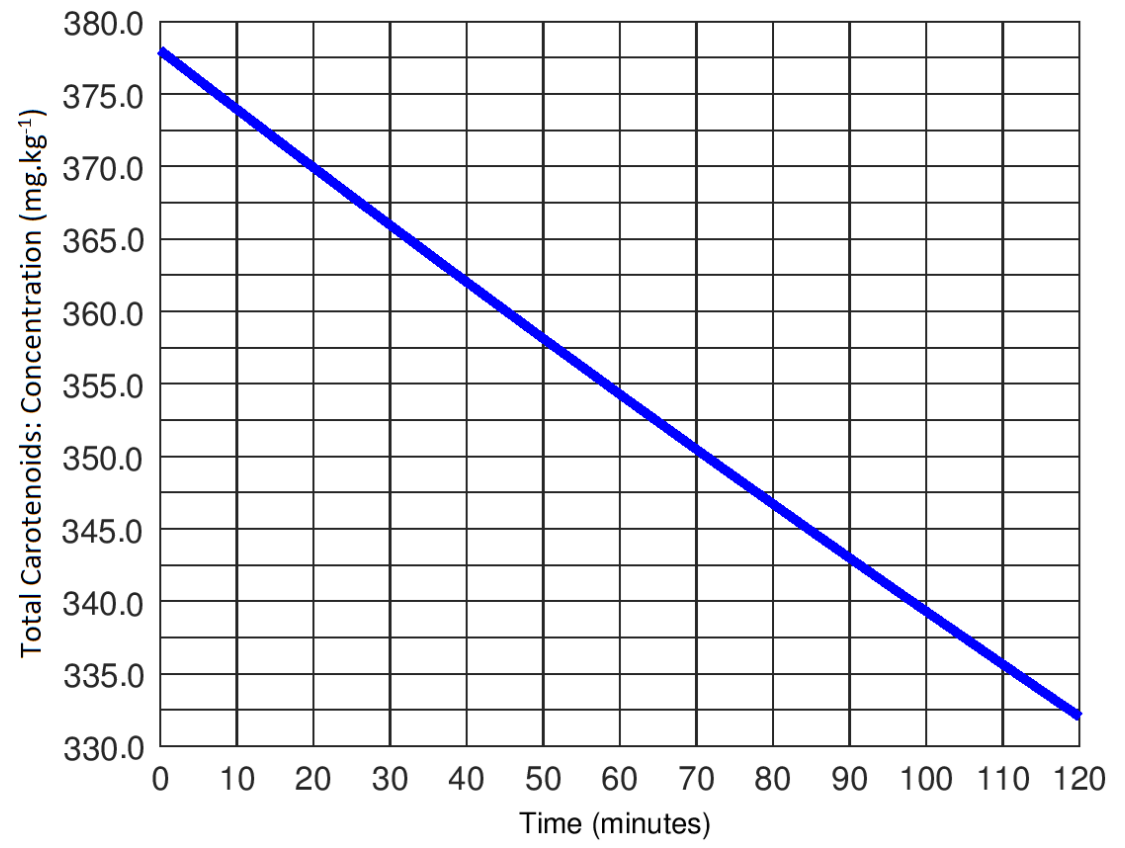

Figure 3: Runge-Kutta Solution: concentration profile for total carotenoids (Range time: 0 to 120 min)

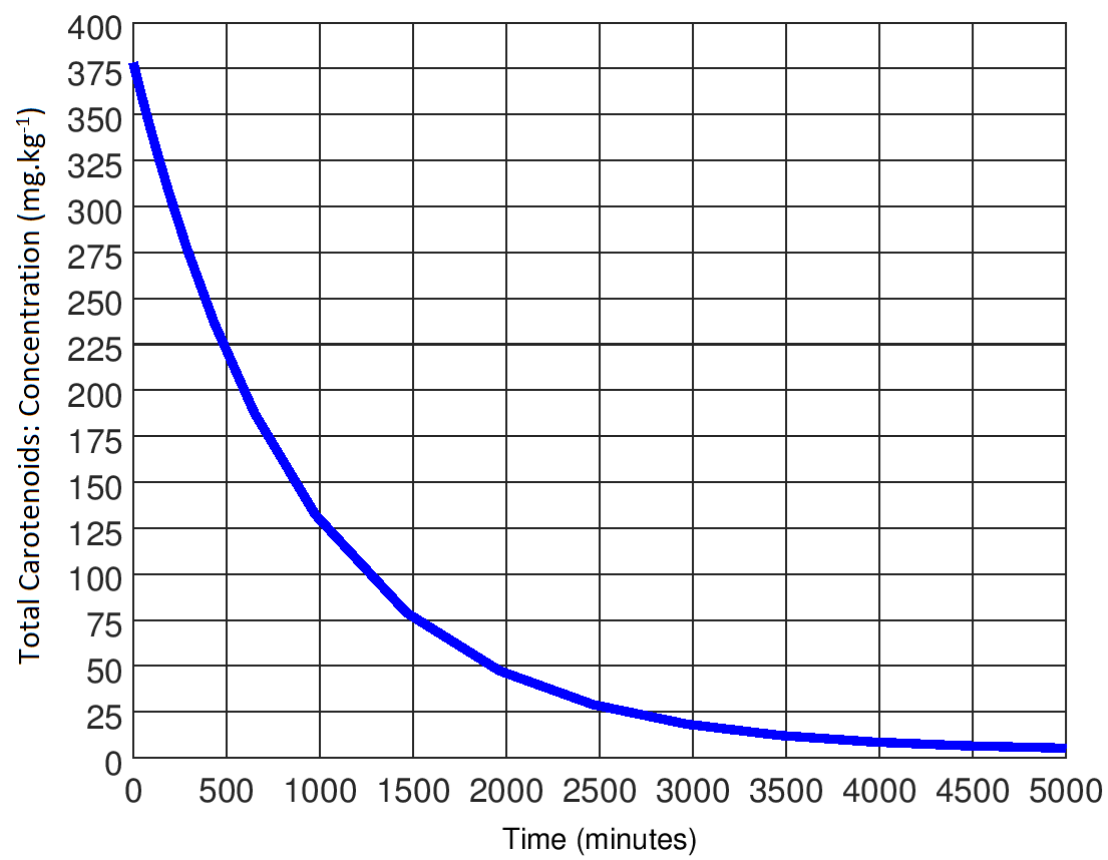

Figure 4: Runge-Kutta Solution: concentration profile for total carotenoids (Range time: 0 to 5000 min) 


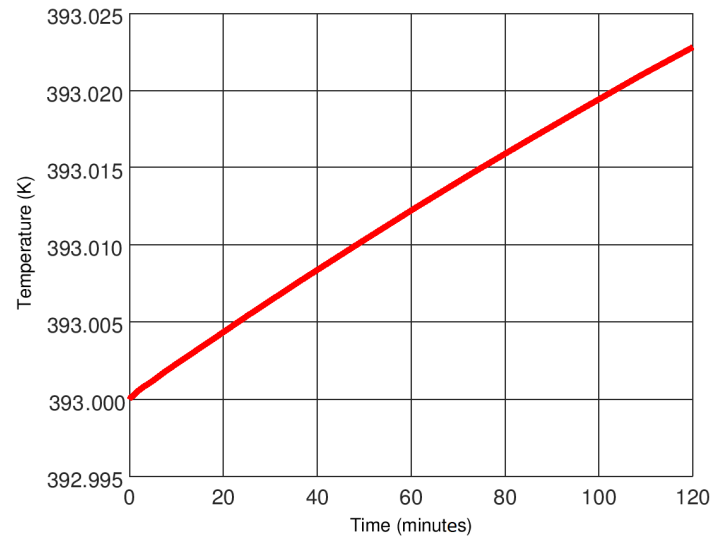

Figure 5: Runge-Kutta Solution: temperature profile for CSTR (Range time: 0 to $120 \mathrm{~min}$ )

2015; Xu, 2000; Zhang et al., 2019).

\subsection{Acid value}

Table 3 shows the mean and standard deviation for the acid values in the mesocarp oil.

As can be observed, the contents of free fatty acids (FFA) were well below the regulatory limits of up to $4 \mathrm{mg} \mathrm{KOH} . \mathrm{g}^{-1}$ for virgin oils for human consumption (CAC, 2015; MAPA, 2006). Also, the acid value $(0.8 \%$, oleic acid) was below the acceptable limit of $3 \%$ economically applied for palm oils. It should be noted that the acid value has already been widely determined in literature for the Macauba kernel oil. It is, therefore, notable that the FFA in kernel oils range from 0.3 to 0.7 (mg KOH.g $\left.{ }^{-1}\right)$, which are usually lower than that of mesocarp oils. In fact, lipolytic enzymes catalyze the decomposition of triglycerides which tends to be most active in mesocarps (CETEC, 1983; Coimbra \& Jorge, 2011; Hiane et al., 2005). Low values of acidity observed for the oils extracted from the Macauba mesocarp and kernel adheres to interesterification purposes, raising the prospects of utilizing Acrocomia aculeata as an alternative source of high-quality raw material, for multi-purpose employments (Nunes et al., 2015). The low acid value observed also enhances chemical interesterification as an appropriate process for the crop productive chain, once it is considered amenable to be scaled up, effi- cient, and feasible to the edible oil industry in general (Tourchi Rudsari et al., 2019; Zhang et al., 2019).

\subsection{Mathematical and predictive modelling}

Figure 1 presents the algorithm developed to run the simulation data supported by the energy and mass balance equations in the GNU Octave Software. Figure 2 describes the algorithm that solves the presented system of differential equations, by $4^{t h}$ order Runge-Kutta method. It is worth noting that that the RungeKutta method has shown stability properties, which has been effective and practical for solving the equations that describe the continuous system, which presenting convergence for the purposes of the present study.

From the perspective of developing a free language program, it should be reasonable to suggest that Figure 1 and Figure 2 might also allow expanding aspects of kinetic applications by sharing solution that complements batch estimations. It is noteworthy that the Octave Program software is compatible with conventional computer systems. It is therefore suggested that its use may not be only a practical solution but also a future possibility for innovative research and development.

Simulation models have been increasingly used to solve problems and to aid in decision-making. Results obtained from computational simulation tend to contribute with practical advantages that also consider predictive capabilities for industrial projects and processes, and to possibly combine raises of efficiency, productivity, and cost reduction.

The total carotenoids concentration and temperature profiles for CSTR are represented by Figures 3, 4 and 5, resulting from simulations.

Figure 3 shows that the total carotenoids concentration profile was continually decreasing regarding the CSTR inlet, starting from $\mathrm{C}_{a o}$ equal to $378 \mathrm{mg} \mathrm{kg}^{-1}$. The temperature profile, shown in Figure 5, was ascending by the addition of flux heat $\left(10^{3} \mathrm{~kJ} \mathrm{~min}^{-1}\right)$. As can be observed, the addition of $1000 \mathrm{~kJ}$ to the process slightly increases the accumulated temperature. Thermodynamic 
$180 \mid$ Valério et al.

Table 2: Fatty acid compositions expressed as a percentage of total fatty acids

\begin{tabular}{|c|c|c|}
\hline \multirow[b]{2}{*}{ Fatty Acid } & \multicolumn{2}{|c|}{ Acrocomia aculeata } \\
\hline & Mesocarp Oil & Kernel Oil \\
\hline Caproic acid (C6:0) & $\mathrm{ND}^{*}$ & $0.35 \pm 0.00^{i}$ \\
\hline Caprylic acid (C8:0) & $0.08 \pm 0.05^{g}$ & $4.38 \pm 0.04^{e}$ \\
\hline Capric acid (C10:0) & $\mathrm{ND}^{*}$ & $3.62 \pm 0.03^{g}$ \\
\hline Undecylic acid (C11:0) & $0.08 \pm 0.04^{g}$ & $\mathrm{ND}^{*}$ \\
\hline Lauric acid (C12:0) & $0.04 \pm 0.01^{g}$ & $37.22 \pm 0.03^{a}$ \\
\hline Myristic acid (C14:0) & $0.07 \pm 0.00^{g}$ & $8.12 \pm 0.02^{c}$ \\
\hline Pentadecylic acid (C15:0) & $0.17 \pm 0.00^{g}$ & $0.03 \pm 0.001$ \\
\hline Palmitic acid (C16:0) & $19.62 \pm 0.56^{b}$ & $6.88 \pm 0.02^{d}$ \\
\hline Palmitoleic acid (C16:1) & $1.68 \pm 0.04^{e f}$ & $0.16 \pm 0.01^{j}$ \\
\hline Margaric acid (C17:0) & $0.09 \pm 0.00^{g}$ & $0.04 \pm 0.001$ \\
\hline Ginkgolic acid (C17:1) & $0.06 \pm 0.00^{g}$ & $0.04 \pm 0.001$ \\
\hline Stearic acid (C18:0) & $5.15 \pm 0.17^{d}$ & $2.90 \pm 0.02^{h}$ \\
\hline Oleic acid (C18:1) & $60.33 \pm 1.18^{a}$ & $32.03 \pm 0.01^{b}$ \\
\hline Linoleic acid (C18:2) & $8.81 \pm 0.32^{c}$ & $3.94 \pm 0.02^{f}$ \\
\hline$\alpha$-Linolenic acid (C18:3) & $0.73 \pm 0.02^{f g}$ & $0.06 \pm 0.00^{k l}$ \\
\hline Arachidic acid (C20:0) & $0.21 \pm 0.00^{g}$ & $0.14 \pm 0.00^{j k}$ \\
\hline Gadoleic acid (C20:1) & $0.07 \pm 0.01^{g}$ & $0.14 \pm 0.01^{j k}$ \\
\hline Behenic acid (C22:0) & $0.14 \pm 0.01^{g}$ & $0.09 \pm 0.01^{j k l}$ \\
\hline Eicosadienoic acid (C20:2) & $1.83 \pm 0.46^{e f}$ & $\mathrm{ND}^{*}$ \\
\hline$\sum S F A^{* *}$ & $25.65 \pm 0.84$ & $63.75 \pm 0.06$ \\
\hline$\sum M U F A^{* * *}$ & $62.14 \pm 1.23$ & $32.32 \pm 0.01$ \\
\hline$\sum P U F A^{* * * *}$ & $11.37 \pm 0.80$ & $3.93 \pm 0.01$ \\
\hline
\end{tabular}

The results represent the mean \pm standard deviation of the analysis performed in triplicate.

Values within the same column - means, followed by the same letter, do not differ by Tukey's test $(\mathrm{p}<0.05)$.

*ND: Not Detected

Note: **) Saturated Fatty Acids; ***) Monounsaturated Fatty Acids; $* * * *)$ Polyunsaturated Fatty Acids.

Table 3: Acid value: Acrocomia aculeata mesocarp oil

\begin{tabular}{cc}
\hline Process Parameters & Dimensions \\
\hline Acid Value $\left(\mathrm{mg} \mathrm{KOH} \mathrm{g}^{-1}\right)$ & $1.6 \pm 0.1$ \\
Acid Value (\% oleic acid) & $0.8 \pm 0.1$ \\
\hline
\end{tabular}


variations were not numerically significant at 120 minutes, due to the endothermic nature of the reaction (Knockaert et al., 2012). For comprehensiveness purposes, Figure 4 shows the thermal degradation profile of total carotenoids in the Acrocomia aculeata oil, over 5000 minutes of thermal processing. The half-life time reaction $\left(t_{1 / 2}\right)$ can be observed at 750 minutes of processing.

From Figure 3 it can be observed that the total carotenoids concentration in the Acrocomia aculeata mesocarp oil varied from around $6.7 \%$ at the first $60 \mathrm{~min}\left(C a_{(60 \mathrm{~min})}: 354.6 \mathrm{mg} \mathrm{kg}^{-1}\right)$, ranging to a maximum degradation of $12.6 \%$ $\left(C a_{(120 \min )}: 331.8 \mathrm{mg} \mathrm{kg}^{-1}\right)$ at the end of the proposed processing. It should be noticed that the research conditions (40 minutes; $393.15 \mathrm{~K}$ ) similar to those of interesterification decrease the initial amount of total carotenoids $(4.22 \%)$ in a CSTR.

Carotenoids losses during food processing have been reported and quantified by previous studies (Mader, 1964; Magosso et al., 2016; Onyewu, Ho \& Daun, 1986; Palmero et al., 2013), although, not often encompassing the effects of processing factors on the thermal degradation. Comparisons between kinetic predictions may become significant when the parameters estimated by batch studies are added to the context. When considering kinetic parameters given by previous studies (Achir et al., 2010; Knockaert et al., 2012), a reduction by around $70 \%$ and $80 \%$ in the carotenoid concentration found for batch systems. Yet, after 60 minutes around $57 \%\left(215 \mathrm{mg} \mathrm{kg}^{-1}\right)$ of the total carotenoid would be degraded as a consequence of temperature supply.

Findings suggest that carotenoid degradation is complex and highly dependent on factors linked to the systems in which they are contained. Hence, process optimization does require product-specific kinetic data. It is essential to consider that process optimization must be supplemented with thermodynamic information for designing efficient processes at industrial scale reactors (Colle, Lemmens, Van Buggenhout, Van Loey \& Hendrickx, 2013; de Carvalho et al., 2020). The simultaneous mass and energy balance, to some extent, brings a significant approach to the real application as proposed in this study.

The highly unsaturated structures of carotenoids make the compounds considerably sensitive to thermal degradation reactions. The rates of degradation tend to increase during thermal treatments as temperature rises. Once the typically used temperature in industrial chemical interesterification processes ranges from 60 to $120{ }^{\circ} \mathrm{C}$, it is recommended to work at milder temperature ranges for extended periods, instead of higher temperatures, in this ambit, for a shorter, to obtain a processed Acrocomia aculeata oil with preserved natural carotenoid content (Achir, Penicaud, Avallone \& Bohuon, 2011; Pardauil et al., 2017; Rodriguez-Amaya, Rodriguez \& AmayaFarfan, 2006).

The use of Acrocomia aculeata oils clearly agrees with efforts for producing different blends of vegetable oils to improve functional performances of structured lipids (Tourchi Rudsari et al., 2019; Xie \& Chen, 2014; Xie et al., 2015), in reference to the increasing demand for natural food and products (Babbar et al., 2015; Cataldo et al., 2016; Oloo et al., 2014).

\section{Conclusion}

A continuous version of the kinetic treatment of total carotenoids degradation that follows a firstorder model has been developed that takes into consideration the thermal effects of conventional processes conditions usually applied for the interesterification of vegetable oils. The findings demonstrate the success of applying the 4 th order Runge-Kutta method to describe the interesterification of Macauba oil, in a CSTR, with minimum carotenoid degradation. Overall, trends of milder degradation tend to be observed when thermal processes are carried out in a continuous system, which has a relatively shorter residence time when compared to the same processes conducted in batch systems. By solving the mass and energy conservation balances, applying the Runge-Kutta method, it was possible to observe the concentration and thermal profile curves. It was possible to verify that the total carotenoids concentration profile was decreasing. The accumulated temperature, in turn, increased slightly, due to the exothermic nature of the reaction. The initial concentration in the oil has not significantly decreased $(4.22 \%)$ when considering

\begin{tabular}{l|l|l|l} 
IJFS & April 2021 & Volume 10 & pages 173-184
\end{tabular} 
time-temperature conditions (40 min; 393,15 K) similar to those of interesterification processes. Evaluations of pilot plant installations should be considered for future studies to validate simulation results presently addressed. Experimental data concerning interesterification may be added for future approaches and procedures, again emphasizing the importance of numerical predictions for practical applications, to contribute to a more realistic industrial design.

\section{Acknowledgements}

The researchers gratefully acknowledged the Brazilian National Council for Scientific and Technological Development - CNPq for their financial support. The authors also wish to thank the Department of Chemical Engineering of the Federal University of Minas Gerais DEQ/UFMG/Brazil for providing facilities to carry out this research.

\section{References}

Achir, N., Penicaud, C., Avallone, S. \& Bohuon, P. (2011). Insight into beta-carotene thermal degradation in oils with multiresponse modeling. Journal of the American Oil Chemists Society, 88(12), 2035-2045. doi:10.1007/s11746-011-1864-2

Achir, N., Randrianatoandro, V. A., Bohuon, P., Laffargue, A. \& Avallone, S. (2010). Kinetic study of beta-carotene and lutein degradation in oils during heat treatment. European Journal of Lipid Science and Technology, 112(3), 349-361. doi:10.1002/ ejlt.200900165

AOCS. (2009). American Oil Chemists' Society - Official Methods and Recommended Practices of the AOCS. Champaign: AOCS Press.

Aparicio-Ruiz, R., Isabel Minguez-Mosquera, M. \& Gandul-Rojas, B. (2011). Thermal degradation kinetics of lutein, beta-carotene and beta-cryptoxanthin in virgin olive oils. Journal of Food Composition and Analysis, 24(6, SI), 811-820. 6th International Congress on Pigments in Food of the Chemical, Biological and Technological Aspects,
Budapest, HUNGARY, JUN 20-24, 2010. doi:10.1016/j.jfca.2011.04.009

Babbar, N., Oberoi, H. S. \& Sandhu, S. K. (2015). Therapeutic and nutraceutical potential of bioactive compounds extracted from fruit residues. Critical Reviews in Food Science and Nutrition, 55(3), 319337. doi:10.1080/10408398.2011.653734

CAC. (2015). Codex Alimentarius Commission. Codex Standard for Named Vegetable Oils: 210-1999. Retrieved from www. fao.org / input / download / standards / 336 / CXS_ 210s_2015.pdf

Cataldo, V. F., López, J., Cárcamo, M. \& Agosin, E. (2016). Chemical vs. biotechnological synthesis of c 13-apocarotenoids: Current methods, applications and perspectives. Applied microbiology and biotechnology, 100 (13), 5703-5718.

CETEC. (1983). Produção de combustiveis líquidos a partir de óleos vegetais (CETEC, Ed.). Fundação Centro Tecnológico de Minas Gerais. Retrieved from 73657

Christie, W. W. (1989). Gas chromatography and lipids. Oily.

Coimbra, M. C. \& Jorge, N. (2011). Characterization of the pulp and kernel oils from syagrus oleracea, syagrus romanzoffiana, and acrocomia aculeata. Journal of Food Science, 76(8), C1156-C1161. doi:10.1111/j. 1750-3841.2011.02358.x

Colle, I. J. P., Lemmens, L., Van Buggenhout, S., Van Loey, A. M. \& Hendrickx, M. E. (2013). Modeling lycopene degradation and isomerization in the presence of lipids. Food and Bioprocess Technology, 6(4), 909-918. doi:10.1007/s11947-011-0714-4

de Carvalho, G. C., de Moura, M. d. F. V., de Castro, H. G. C., da Silva Junior, J. H., da Silva, H. E. B., dos Santos, K. M. \& Rocha, Z. M. S. (2020). Influence of the atmosphere on the decomposition of vegetable oils: Study of the profiles of FTIR spectra and evolution of gaseous products. Journal of Thermal Analysis and Calorimetry, 140(5), 2247-2258. doi:10.1007/ s10973-019-08960-9

Dijkstra, A. J. (2015). Interesterification, chemical or enzymatic catalysis. Lipid Technology, 27(6), 134-136. 
Dinh, L. N., Sun, T. C. \& McLean, W., II. (2016). Temperature-dependent kinetic prediction for reactions described by isothermal mathematics. Journal of Physical Chemistry A, 120(39), 7617-7623. doi:10.1021/acs.jpca. $6 \mathrm{~b} 08219$

Evaristo, A. B., Saraiva Grossi, J. A., Pimentel, L. D., Goulart, S. d. M., Martins, A. D., dos Santos, V. L. \& Motoike, S. (2016). Harvest and post-harvest conditions influencing macauba (acrocomia aculeata) oil quality attributes. Industrial Crops and Products, 85, 63-73. doi:10.1016/j.indcrop. 2016.02.052

Fasina, O. O. \& Colley, Z. (2008). Viscosity and specific heat of vegetable oils as a function of temperature: $35 \mathrm{c}$ to $180 \mathrm{c}$. International Journal of Food Properties, 11(4), 738-746. doi:10.1080/10942910701586273

Goula, A. M. (2013). Ultrasound-assisted extraction of pomegranate seed oil-kinetic modeling. Journal of Food Engineering, 117(4), 492-498. doi:10.1016/j.jfoodeng.2012.10. 009

Grimaldi, R., Gonçalves, L. A. G. \& Ando, M. Y. (2005). Otimização da reação de interesterificação química do óleo de palma. Química Nova, 28, 633-636. doi:10.1590 / S0100 40422005000400015

Guo, H., Hu, C., Qian, J. \& Wu, D. (2012). Determination of underivatized long chain fatty acids using hplc with an evaporative light-scattering detector. Journal of the American Oil Chemists Society, 89(2), 183-187. doi:10.1007/s11746-011-1898-5

Hiane, P. A., Ramos Filho, M. M., Ramos, M. I. L. \& Macedo, M. L. R. (2005). Bocaiúva, acrocomia aculeata (jacq.) lodd., pulp and kernel oils: Characterization and fatty acid composition. Brazilian Journal of Food Technology, 8(3), 256-259.

Knockaert, G., Pulissery, S. K., Lemmens, L., Van Buggenhout, S., Hendrickx, M. \& Van Loey, A. (2012). Carrot beta-carotene degradation and isomerization kinetics during thermal processing in the presence of oil. Journal of Agricultural and Food Chemistry, 60(41), 10312-10319. doi:10.1021/ jf3025776
Koidis, A. \& Boskou, D. (2015). Virgin olive oil: Losses of antioxidant polar phenolic compounds due to storage, packaging, and culinary uses. In Processing and impact on active components in food (pp. 267-274). Elsevier.

Mader, I. (1964). Beta-carotene: Thermal degradation. Science, $144(3618)$, 533-534.

Magosso, M. F., Carvalho, P. C., Shneider, B. U. C., Pessatto, L. R., Pesarini, J. R., Silva, P. V. B., ... Oliveira, R. J. (2016). Acrocomia aculeata prevents toxicogenetic damage caused by the antitumor agent cyclophosphamide. Genetics and Molecular Research, 15(2). doi:10.4238/gmr . 15027816

MAPA. (2006). Ministry of Agriculture Livestock and Food Supply. Technical Regulation on the Identity and Quality of Refined Vegetable Oils: Normative Instruction 49. Brasilia.

Norizzah, A. R., Chong, C. L., Cheow, C. S. \& Zaliha, O. (2004). Effects of chemical interesterification on physicochemical properties of palm stearin and palm kernel olein blends. Food Chemistry, 86(2), 229-235. doi:10.1016/j.foodchem.2003.09.030

Nunes, A. A., Favaro, S. P., Galvani, F. \& Miranda, C. H. B. (2015). Good practices of harvest and processing provide high quality macauba pulp oil. European Journal of Lipid Science and Technology, 117(12), 2036-2043. doi:10.1002/ejlt.201400577

Oloo, B. O., Shitandi, A. A., Mahungu, S., Malinga, J. B. \& Ogata, R. B. (2014). Effects of lactic acid fermentation on the retention of b-carotene content in orange fleshed sweet potatoes. International Journal of Food Studies, 3(1).

Onyewu, P. N., Ho, C. T. \& Daun, H. (1986). Characterization of beta-carotene thermaldegradation products in a model food system. Journal of the American Oil Chemists Society, 63(11), 1437-1441. doi:10.1007/ BF02540870

Palmero, P., Lemmens, L., Ribas-Agusti, A., Sosa, C., Met, K., Umutoni, J. d. D., ... Van Loey, A. (2013). Novel targeted approach to better understand how natural structural barriers govern carotenoid 
in vitro bioaccessibility in vegetable-based systems. Food Chemistry, 141(3), 20362043. doi:10.1016/j.foodchem.2013.05.064

Pardauil, J. J. R., de Molfetta, F. A., Braga, M., de Souza, L. K. C., Filho, G. N. R., Zamian, J. R. \& da Costa, C. E. F. (2017). Characterization, thermal properties and phase transitions of amazonian vegetable oils. Journal of Thermal Analysis and Calorimetry, 127(2), 1221-1229. doi:10.1007/ s10973-016-5605-5

Parducci, L. G. \& Fennema, O. (1978). Rate and extent of enzymatic lipolysis at subfreezing temperatures. Cryobiology, 15(2), 199-204.

Petrauskaite, V., De Greyt, W., Kellens, M. \& Huyghebaert, A. (1998). Physical and chemical properties of trans-free fats produced by chemical interesterification of vegetable oil blends. Journal of the American Oil Chemists Society, 75(4), 489-493. 88th AOCS Annual Meeting and EXPO, SEATTLE, WASHINGTON, MAY 11-14, 1997. doi:10.1007/s11746-998-0252-z

Rodriguez-Amaya, D. B., Rodriguez, E. B. \& Amaya-Farfan, J. (2006). Advances in food carotenoid research: Chemical and technological aspects, implications in human health. Malaysian Journal of Nutrition, 12(1), 101-121.

Rodríguez, A., Castro, E., Salinas, M. C., López, R. \& Miranda, M. (2001). Interesterification of tallow and sunflower oil. Journal of the American Oil Chemists' Society, 78(4), 431-436.

Sampaio, K. A., Ayala, J. V., Silva, S. M., Ceriani, R., Verhé, R. \& Meirelles, A. J. A. (2013). Thermal degradation kinetics of carotenoids in palm oil. Journal of the American Oil Chemists' Society, 90(2), 191-198.

Singh, A., Singh, A. P. \& Ramaswamy, H. S. (2015). Computational techniques used in heat transfer studies on canned liquidparticulate mixtures. Trends in Food Science \& Technology, 43(1), 83-103.

Tourchi Rudsari, M., Najafian, L. \& Shahidi, S. A. (2019). Effect of chemical interesterification on the physicochemical characteristics of bakery shortening produced from palm stearin and ardeh oil (sesamum in- dicum) blends. Journal of Food Processing and Preservation, 43(10), e14101.

Uzun, H. \& Ibanoglu, E. (2018). Oxidation kinetics of hazelnut oil treated with ozone. Grasas y Aceites, 68(4), 222.

Valério, P. P. (2017). Óleos comestíveis extraídos mecanicamente de frutos da palmeira acrocomia aculeata como novos alimentos: Processamento, caracterização e cinética de degradação térmica de compostos bioativos (Doctoral dissertation, Universidade Federal de Minas Gerais). Retrieved from http: //hdl.handle.net/1843/BUOS-AUVMGU

Xie, W. \& Chen, J. (2014). Heterogeneous interesterification of triacylglycerols catalyzed by using potassium-doped alumina as a solid catalyst. Journal of Agricultural and Food Chemistry, 62(43), 10414-10421. doi:10.1021/jf503726a

Xie, W., Yang, X. \& Zang, X. (2015). Interesterification of soybean oil and methyl stearate catalyzed by guanidine-functionalized sba-15 silica. Journal of the American Oil Chemists Society, 92(6), 915-925. doi:10. 1007/s11746-015-2651-2

$\mathrm{Xu}$, X. B. (2000). Production of specificstructured triacylglycerols by lipasecatalyzed reactions: A review. European Journal of Lipid Science and Technology, 102(4), 287-303.

Zhang, Z., Lee, W. J., Zhou, H. \& Wang, Y. (2019). Effects of chemical interesterification on the triacylglycerols, solid fat contents and crystallization kinetics of palm oil-based fats. Food \& Function, 10(11), 7553-7564. doi:10.1039/c9fo01648a 